\title{
The Role of Referring Centres in the Tragedy of 'Unbooked' Patients
}

\section{Oluwafemi Kuti, Francis O. Dare and Solomon O. Ogunniyi.}

Department of Obstetrics and Gynaecology, Obafemi Awolowo University Teaching Hospitals Complex, Ile-Ife, Nigeria.

\begin{abstract}
Context: Despite the proliferation of health centres in Nigeria, the number of 'unbooked' obstetric patients seen in tertiary institutions remains high, and their obstetric outcome is usually poor. Since many of these patients are referred from these health centres, it is important to determine their contributions to the tragedy of these patients.

Objectives: To assess the cuntribution of referring centres to the morbidity and mortality seen in unbooked patients.

Study Design and Setting: Cross-sectional study at a University Teaching Hospital in llesa, Nigeria.

Subjects and Methods: All unbooked patients admitted into the obstetric wards of the Wesley Guild Hospital, Ilesa between January and July 2000 had a proforma completed to record information on age, parity, social class, source of referral, the management given at the source of referral and the condition of the patient on admission.

Results: Of the 148 unbooked patients admitted during the study period, $87(58.8 \%)$ received care in various referring centres. Sixty-five of these 87 patients (74.7\%) were mismanaged. The sources of referral were traditional birth attendants (TBA), mission houses and private hospitals where $100 \%, 87.5 \%$ and $80 \%$ respectively of the patients were mismanaged before being allowed to come to the hospital. Among referred patients, $62.1 \%$ were received in poor clinical condition compared to $39.3 \%$ of those who did not receive prior care anywhere. $(P<0.05)$

Conclusion: Inadequate care at sources of referral is a major contributor to morbidity and mortality in unbooked patients. We suggest that these health facilities be supervised and monitored to reduce the current high morbidity and mortality among unbooked patients.
\end{abstract}

Key Words: Unbooked; Antenatal; Referral Source; Obstetric Outcome. [Trop J Obstet Gynaecol, 2001, 18: 24-26]

\section{Introduction}

Unbooked patients continue to constitute a major source of obstetric morbidity and mortality in developing countries ${ }^{1}$. Despite the increase in the number of health institutions in Nigeria, the number of unbooked patients remains high and the problems from them remain a serious source of concern for reproductive health care providers ${ }^{2}$.

Previous authors have reviewed the obstetric performance of unbooked patients and have found it to be generally bad, with poor maternal and perinatal outcomes ${ }^{2,3,4,5}$. Many of these patients, sadly, had received care in one healthy facility or the other before presentation ${ }^{6}$. The objective of this study is to assess the contribution of these referring centres to the poor obstetric performance of unbooked patients.

\section{Materials and Methods:}

In this study, a mother was regarded as 'unbooked' if she was admitted as an emergency, with no care at all in any health facility during the pregnancy, or if she had been referred to our unit from another hospital or health facility as an emergency.

All unbooked patients admitted into the obstetric wards of Wesley Guild Hospital, Ilesa, Nigeria between January and July 2000 were recruited to the study. A proforma was completed for each patient on admission to obtain information on the age, parity, social class and source of admission.
When a patient was referred from a health facility, information on management in such centres was obtained from the referral letter and from direct interview of patients and relatives. A patient was regarded as having been mismanaged at the referring centre if the diagnosis and/or treatment given were wrong and if there had been delay in referring the patient.

The clinical condition of the patient on admission was also assessed. For the purpose of this study, this was classified into good, stable or poor.

Good: Patients referred because of the risk of developing problem, but complications have not yet developed.

Stable: Patients who came promptly.at the onset of a particular problem with stable vital signs, without added complications, from previous mismanagement or delay in presentation.

Poor: Patients admitted with abnormal vital signs or with superimposed complications either as a result of mismanagement or delay in presentation.

Statistical analysis was by the $\mathrm{x}^{2}$ test, with the level of significance set at $\mathrm{P}<0.05$.

Correspondence: Dr. O. Kuti, Department of Obstetrics \& Gynaecology, Obafemi, Awolowo University Teaching Hospitals Complex, Ile-Ife, Osun State, Nigeria. 


\section{Results}

During the period of study, 148 unbooked patients were admitted into the obstetric unit. Twenty-four (16.2\%) presented during the antenatal Feriod while $77(52.0 \%)$ and $47(31.8 \%)$, were admitted in labour and the postpartum period respectively. The mean age of the mothers wạs 26.7

years (Range 16-40 years) and the mean parity was 2 (range $0-8$ ). Eighty-seven $\$ 58.8 \%$ ) of the patients actually received care in one centre or the other while 61 $(41.2 \%)$ did not have any care before presentation. Table 1 shows the distribution of the patients according to referring centres. Among patients that received care before presentation, the majority $(83.9 \%)$ were seen in orthodox health care institutions (maternity centres and hospitals). Among the patients not registered for care anywhere 35 (57.4\%) were living in llesa and 45 (73.8\%) were living within one-hour drive from Wesley Guild Hospital.

Table 2 shows the proportion of patients mismanaged by the different referring centres. Altogether, $74.7 \%$ of the

\section{Table 1}

Distribution of Unbooked Patients

According to Source of Referral

\begin{tabular}{|l|c|}
\hline Source of Admission & Number of Patients \\
\hline Private Hospital & $5(3.4 \%)$ \\
TBA* & $6(4.1 \%)$ \\
Mission House & $8(5.4 \%)$ \\
General Hospital & $13(8.8 \%)$ \\
Private Maternity & $22(14.9 \%)$ \\
Government Maternity & $33(22.3 \%)$ \\
NONE & $61(41.2 \%)$ \\
TOTAL & $\mathbf{1 4 8}$ \\
\hline
\end{tabular}

${ }^{*} T B A=$ Traditional Birth Attendants.

**NONE $=$ Mothers who did not register anywhere prior to presentation. patients from all the referring centres were mismanaged. Out of the 87 patients from all the referral centres, $62.1 \%$ were received in poor clinical condition compared with $39.3 \%$ for those who did not receive any care prior to presentation $(P<0.05)$. Significantly more patients from orthodox institutions were received in poor clinical condition compared with those with no prior care $(58.9 \%$ vs. $39.3 \% ; P<0.05)$. Although more of the patients from unorthodox centres were received in poor clinical state compared with those from orthodox centres, $(78.6 \%$ vs. $58.9 \%$ ), the difference was not statistically significant $(P<=0.165)$. Table 3 shows the clinical condition of the patients in relation to the different sources of admission.

There were five maternal deaths in the unit during the study period and all of them were unbooked patients, giving a maternal mortality ratio of 3,378 per 100,000 . These patients were referred, one each, from a mission house private hospital and government maternity centre while the last two were from 2 private maternity homes.

\section{Table 2}

Care of Unbooked Patients at Referral Source

\begin{tabular}{|l|c|c|}
\hline $\begin{array}{l}\text { Source of } \\
\text { Admission }\end{array}$ & $\begin{array}{c}\text { Total Number } \\
\text { of Patients }\end{array}$ & $\begin{array}{c}\text { Number } \\
\text { Mismanaged }\end{array}$ \\
\hline TBA* & 6 & $6(100 \%)$ \\
Mission House & $\mathbf{8}$ & $7(87.5 \%)$ \\
Private Hospital & 5 & $4(80.0 \%)$ \\
Private Maternity, & 22 & $17(77.3 \%)$ \\
Government Maternity & 33 & $25(75.8 \%)$ \\
General Hospital & 13 & $6(46.2 \%)$ \\
\hline
\end{tabular}

${ }^{*} T B A=$ Traditional Birth Attendants.

\section{Table 3}

Condition of Unbooked Patients on Admission from the Different Referral Sources

\begin{tabular}{|l|c|c|c|c|}
\hline Source of & Number of & \multicolumn{3}{|l|}{ Condition on Admission } \\
\cline { 3 - 5 } Admission & Patients & Poor & Stable & Good \\
\hline TBA & 6 & $5(83.3 \%)$ & $1(16.7 \%)$ & - \\
Private Hospital & 5 & $4(80.0 \%)$ & $1(20.0 \%)$ & - \\
Mission House & 8 & $6(75.0 \%)$ & $2(25.0 \%)$ & - \\
Government maternity & 33 & $22(66.7 \%)$ & $9(27.3 \%)$ & $2(6.1 \%)$ \\
Private maternity & 22 & $14(63.6 \%)$ & $7(31.9 \%)$ & $1(4.6 \%)$ \\
General hospital & 13 & $3(23.1 \%)$ & $6(46.2 \%)$ & $4(30.8 \%)$ \\
NONE & 61 & $24(39.3 \%)$ & $28(45.9 \%)$ & $9(14.8 \%)$ \\
\hline
\end{tabular}




\section{Discussion}

It is surprising to note from this study that as many as $41.2 \%$ of the unbooked patients did not register for care anywhere prior to presentation. This figure is much higher than the $13.2 \%$ reported by Iloabachie and Uche in Enugu among their own group of unbooked patients ${ }^{2}$. This may be due to the current hardship in the country, which is compounded by the recent increase in the cost of antenatal care. The problem in this group of patients cannot be accessibility to medical services alone as formerly thought ${ }^{3}$, as more than fifty percent of the patients live within Ilesa and seventy percent were within one hour's drive of Wesley Guild Hospital.

The study revealed that among patients who had accepted the need for antenatal care, the quality of care leaves much to be desired as majority of them were mismanaged. Although the majority of these patients were seen in orthodox health care institutions (maternity centres and hospitals), the performance of these primary and secondary health institutions in the management of pulients was largely unsatisfactory. They were only marginally better than the TBA and the churches. The poor performance of private hospitals was particularly disturbing. This is probably because they may attempt to undertake procedures beyond their ability.

The high maternal mortality ratio among unbooked patients in this series is similar to the findings of other authors $1,2,3$. This study suggests that the problem of unbooked patients has to be addressed on two main fronts. One is to make antenatal care facilities affordable to patients in order to increase the number of booked patients. The second is to increase government supervision of health facilities and institute control measures so as to ensure good standard of care in the registered health centres. As suggested by Harrison ${ }^{6}$, and supported by the findings in this paper, real progress in reducing maternal mortality and morbidity can only be made by directing attention on the training and proper utilization of health personnel.

Mismanagement of patients at the referring centres is a major contribution to the tragedy of unbooked patients. To reduce the current high morbidity and mortality among these patients, existing health facilities should be adequately supervised and monitored.

\section{References}

1. Ozumba $\mathrm{BC}$, Uchegbu $\mathrm{H}$. Incidence and management of obstructed labour in "Eastern Nigeria. Aust NZ J Obstet Gynaecol 1991; 31:213-216.

2. Iloabachie GC, Uche GO. Obstetric performance in unbooked patients at the University of Nigeria Teaching Hospital Enugu. Trop J Obstet Gynaecol. $1985 ; 5: 4\rfloor-43$.

3. Hamilton RA, Perlman T, de Souza JJL. The unbooked patient II. Outcome of Pregnancy in unbooked coloured patients. S Afr Med J. 1987; 71: 31-34.

4. Adelusi B, Al-Nuaim LA., Chowdhury N, Abotalib Z, Moghraby S, Kangave D. Socio-demographic characteristics of the "Unbooked mother". West Afr $J$ Med. 1999; 18: 191-195.

5. Abotalib Z, Adelusi B, al Mestrar A, al Nuaim A Chowdhury N, Kangave D: Obstetric outcome in the unbooked mother. E Afr Med J. 1998; Feb. 75(2): 102-6

6. Harrison K.A.: Maternal mortality in developing countries Br J Obstet Gynaecol. 1989; 96:1-3 